\title{
A STUDY OF MYCOBACTERIUM FORTUITUM (RANAE)
}

\author{
S. R. Pattyn, ${ }^{*}$ M. Magnusson, $\dagger$ J. L. Stanford $\ddagger$ and J. M. Grange $\$$ \\ Prins Leopold Instituut voor Tropische Geneeskunde, B 2000 Antwerp, Belgium,* Tuberculin \\ Department, Statens Seruminstitut, Copenhagen, Denmark, $\dagger$ and School of Pathology, \\ Middlesex Hospital Medical School, London $\ddagger$
}

MYCOBACTERIUM RANAE was first isolated from frogs by Kuster (1905), who called it the frog tubercle bacillus. It belonged to those organisms formerly known as the "cold-blooded" type of tubercle bacilli. The organism was recognised as a distinct species and given the epithet ranae by Bergey et al. (1923). A number of taxonomic studies performed before the Second World War included this species and established its separate status from Myco. chelonei and other fast-growing mycobacteria (Mudd, 1925; Wilson, 1925; Furth, 1926; Furth and Aronson, 1927; Aronson, 1929; Griffith, 1930; Gordon, 1937). da Costa Cruz (1938) isolated a similar organism from an injection abscess and named it Myco. fortuitum without performing comparative studies with Myco. ranae. Darzins (1950), Penso et al. (1952) and Bojalil, Cerbon and Trujillo (1962) described Myco. giae, Myco. minetti and Myco. peregrinum. All have subsequently been found to be Myco. ranae (Gordon and Mihm, 1959; Stanford and Gunthorpe, 1969; Kubica et al. 1972) although the species is not homogeneous (Bönicke, 1966; Stanford and Gunthorpe, 1969; Jenkins, Marks and Schaefer, 1971). Unfortunately the status of Myco. ranae has been somewhat compromised by the accidental distribution of strains of Myco. smegmatis as Myco. ranae by the American Type Culture Collection in the years immediately after the Second World War. In view of this, and because the name Myco. fortuitum has come into common use, Runyon (1972) has recommended that ranae be discarded in favour of the later epithet fortuitum, despite the common use of the latter for strains of Myco. chelonei; and the Judicial Commission of the International Committee on Systematic Bacteriology of the International Association of Microbiological Societies have since ruled in favour of the adoption of fortuitum in place of ranae.

In this study three laboratories have co-operated to perform a detailed analysis of a group of strains of Myco. fortuitum including the type strains of each of the organisms whose names are now considered synonymous with it, with the exception of Myco. minetti. Each of the three participating laboratories used a different immunological method, and two also performed biochemical and cultural tests.

MATERIALS AND METHODS

Strains

The Antwerp laboratory supplied the following nine strains: nos. $800,1811,1812$ and 1900 , from injection abscesses in Kinshasa, Zaire; no. 1828 from a zoo aquarium in Belgium;

Received 12 Mar. 1973; accepted 16 May 1973.

J. MED. MICROBIOL.,VOL. 7 (1974) 
nos. 1954 and 2076 from contaminated laboratory cultures in Belgium; nos. 2040 and 2042 from contaminated laboratory cultures in Kinshasa.

The Copenhagen laboratory supplied the following nine strains: nos. 19 and 20, isolated in Denmark from sputum by Dr H. C. Engbaek; no. 31, isolated in Denmark from gastric washings by Dr H. C. Engbaek; no. 411, a bacteriophage-free variant of strain "Ugoji" (see below) obtained from Dr I. Baess; no. 516, Myco. peregrinum 128-1, obtained from Dr L. F. Bojalil; no. 615, strain " Ugoji", isolated from an injection abscess by Dr A. Beck; no. 927, Myco. fortuitum, ATCC 6841, type strain; no. 928, Myco. giae (ATCC no. 11440) type strain; no. 931, Myco. peregrinum (ATCC no. 14467) type strain.

The London laboratory supplied the following 10 strains: no. 4 (NCTC no. 8573), from a mandibular abscess; no. 5 (NCTC no. 2006) from a terrapin; no. 33, strain "Ugoji" (see above); no. 81, Myco ranae, (NCTC no. 2891) type strain; nos. 108 and 109, isolated from sputa of Welsh miners by Dr J. Marks; no. 487, isolated from an injection abscess in Zaire by Professor F. Gatti; no. 491, isolated in England from sputum; no. 630 (ATCC no. 23021); no. 632 (ATCC no. $23023 \equiv$ ATCC no. 14467; see no. 931 above).

\section{Methods used in the Antwerp laboratory}

Cultural and biochemical methods. Colonial morphology on corn-meal agar, growth at different temperatures, methods for the determination of the reduction of ferric ammonium citrate, production of acid from carbohydrates, deamination of putrescine and phosphatase activity have been the subject of a recent review (Pattyn and Portaels, 1972).

Agglutination test. The use of sero-agglutination tests for the identification of rapidly growing mycobacteria has been described by Pattyn (1970), who found that strains of Myco. fortuitum were divisible into two groups provisionally referred to as the Fortuitum and Peregrinum types. In the present study suspensions of the strains were tested against the Fortuitum and Peregrinum type antisera using a working dilution of four times the strength of the final titre. The method for preparing the antisera and performing the agglutination test is described elsewhere (Pattyn, 1968).

\section{Methods used in the Copenhagen laboratory}

Intradermal test in guinea-pigs. The method of typing based on the specificity of the delayed type of skin reaction in guinea-pigs has been described previously (Magnusson and Mariat, 1968).

In this study 28 experiments were performed on 390 guinea-pigs. The results obtained are expressed as specificity differences (spd) which are calculated as follows:

$$
\text { spd }=(A a+B b)-(A b+B a) .
$$

$A a$ is the average homologous reaction (in $\mathrm{mm}$ ) obtained with sensitin $A$ in animals sensitised with strain $a$, and $A b$ is the average heterologous reaction obtained with sensitin $A$ in animals sensitised with strain $b$; likewise $B b$ and $B a$ represent the average homologous and heterologous reactions obtained with sensitin $B$.

\section{Methods used in the London Laboratory}

Cultural and biochemical tests. For studies of colonial appearance, strains were plated on thick layers of $1.0 \%$ nutrient agar. Young colonies were examined with a plate microscope (magnification $\times 40$ ) using reflected and transmitted light.

Each strain was tested for its ability to oxidise sugars (Gordon and Smith, 1953), split amides (Bönicke, 1962), reduce nitrate (Bönicke, 1962, after Virtanen, 1960), hydrolyse Tween 80 within 10 days (Wayne, Doubek and Russel, 1964) and split phenolphthalein sulphate within 3 days (Whitehead, Wildy and Engbaek, 1953).

Immunodiffusion analysis. The methods have been described previously (Stanford and Beck, 1968; Stanford and Gunthorpe, 1971). Antigens were prepared by ultrasonic disintegration from each of the strains, and antisera to strains 632 and 81 were prepared in rabbits. Antisera to strains 4 and 108 were available from previous studies (Stanford and 


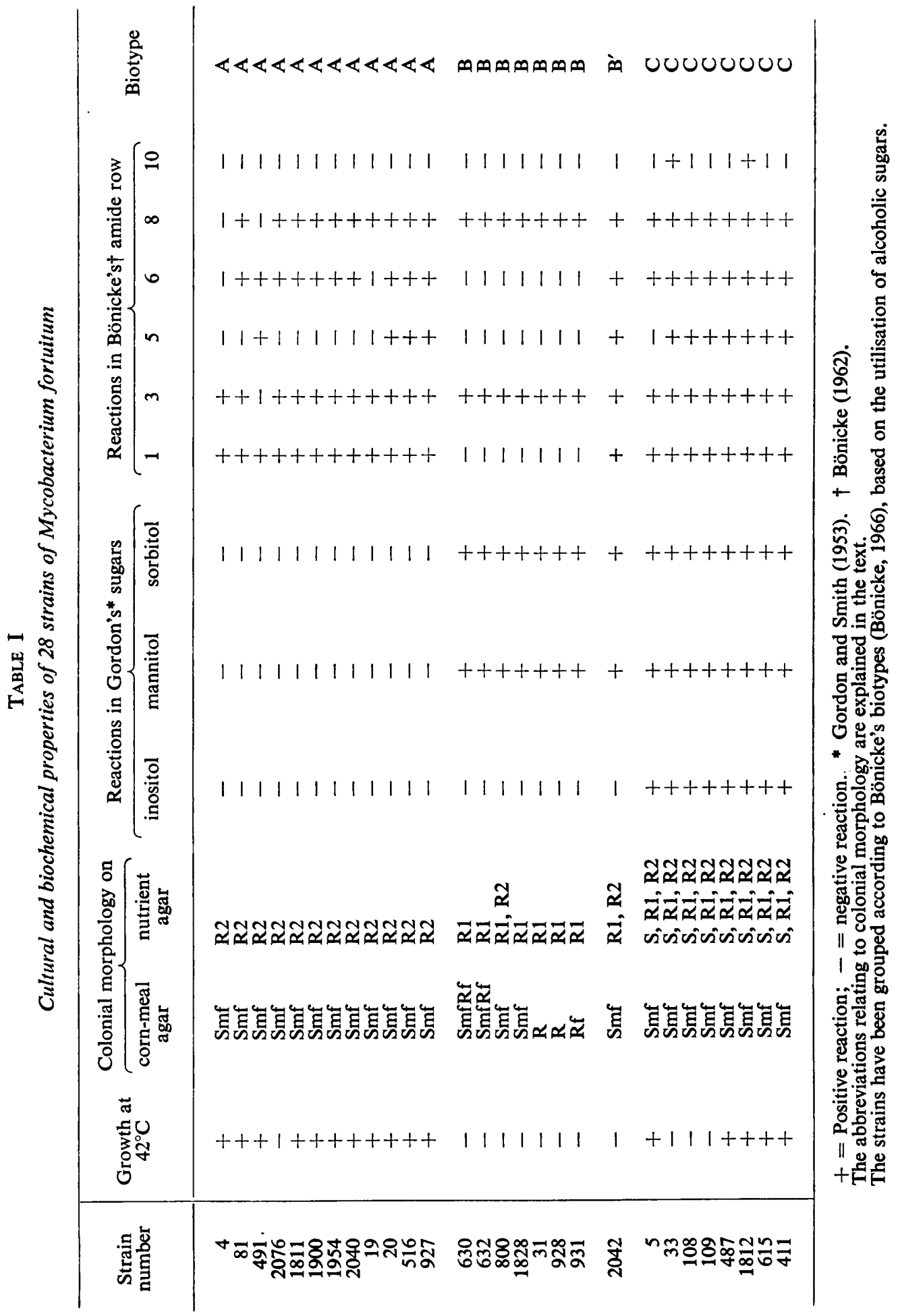


Gunthorpe, 1969). Antigens of each strain were tested against each antiserum and comparisons were made between the precipitation patterns.

Lipid chromatography. The lipid composition of the strains was studied by the thin-layer chromatographic technique of Marks and Szulga (1965). The thin-layer plates were prepared from silica gel (BDH laboratory reagents) and the solvent used for the chromatographic run was a mixture of $150 \mathrm{ml} \mathrm{n}$-propanol, $6 \mathrm{ml} \mathrm{0.880} \mathrm{ammonia} \mathrm{and} 44 \mathrm{ml}$ distilled water.

\section{RESULTS}

\section{Colonial appearance}

Three types of colony were observed on corn-meal agar; smooth filamentous (Smf), rough filamentous ( $R f)$ and rough $(R)$. Twenty-three strains were of the Smf type, one was $\mathrm{Rf}$, two were $\mathrm{R}$ and two were a mixture of Smf and Rf types.

On nutrient agar three colonial forms were observed and are referred to as S, R1 and R2. S colonies were circular, dome-shaped, glossy and mucoid in consistency. R1 colonies were flat, opaque, spreading, crenated and brittle. R2 colonies possessed a central papilla and a slightly irregular edge; they were non-glossy in reflected light and had a granular appearance in transmitted light. The distribution of colonial forms in relation to biotype (see below) is shown in table I.

\section{Biochemical tests}

All strains oxidised glucose, mannose, trehalose and fructose, and none oxidised arabinose, dulcitol, erythritol, galactose, lactose, raffinose, rhamnose or xylose. In Bönicke's amide row, all strains with one exception split urea, and with one further exception allantoin; none split benzamide, isonicotinamide, salicylamide or succinamide. All the strains produced arylsulphatase within 3 days, hydrolysed Tween 80 within 10 days, reduced nitrate and ferric ammonium citrate, produced phosphatase and deaminated putrescine.

The results in which strains differed from one another are shown in table I. The strains have been grouped according to Bönicke's biotypes A, B and C (Bönicke, 1966). Biotype $B^{\prime}$ oxidised the same carbohydrates as the strains of biotype $B$ but possessed the same amidase spectrum as the strains of biotype $C$.

\section{Sensitin typing}

On the basis of the spd values shown in table II, and by means of the criteria for their utilisation in classification reported previously (Magnusson and Mariat, 1968), four groups containing five, four, 12 and five strains could be distinguished. The remaining two strains (nos. 108 and 109) could not be placed in any of these groups.

\section{Agglutination typing}

Twelve strains were agglutinated by the Fortuitum antiserum (type F) and a further 12 strains were agglutinated by the Peregrinum antiserum (type P). The remaining four strains were too rough to be tested by this technique. The findings are given in detail in the first column of results in table III. 


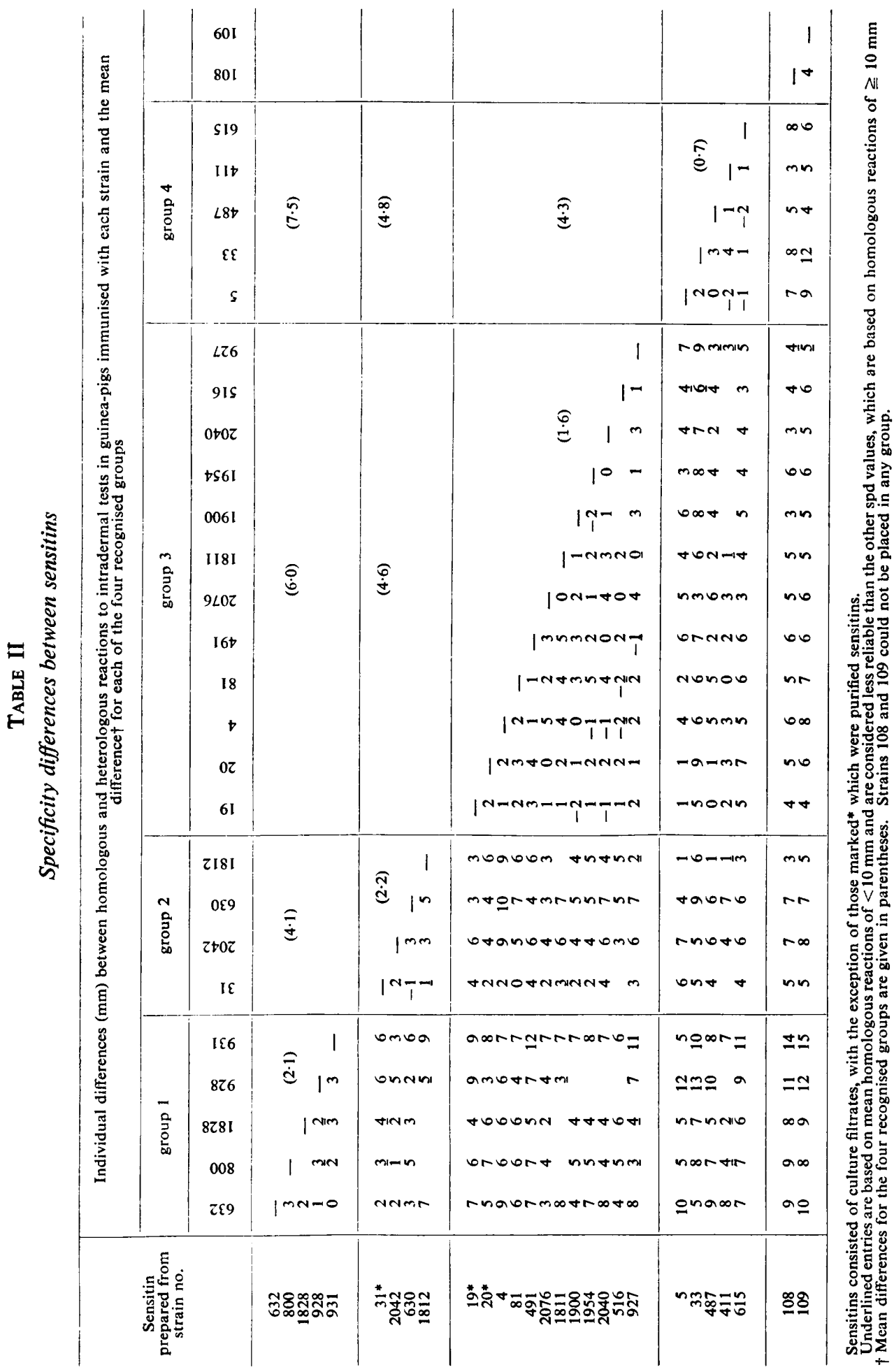




\section{Immunodiffusion analysis}

Twenty-one of the strains could be allocated to the four serotypes previously described (Stanford and Gunthorpe, 1969) on the basis of the presence or absence of serotype-specific antigens. One strain (no. 4) classified as serotype

TABLE III

Division of 28 strains into three groups on the basis of five tests

\begin{tabular}{|c|c|c|c|c|c|}
\hline Strain & $\begin{array}{c}\text { Agglutination } \\
\text { type }\end{array}$ & $\begin{array}{c}\text { Sensitin-test } \\
\text { type }\end{array}$ & $\begin{array}{c}\text { Immunodiffusion } \\
\text { type }\end{array}$ & $\begin{array}{c}\text { Lipid- } \\
\text { chromatography } \\
\text { type }\end{array}$ & Biotype \\
\hline $\begin{array}{r}4 \\
81 \\
491 \\
2076 \\
1811 \\
1900 \\
1954 \\
2040 \\
19 \\
20 \\
516 \\
927\end{array}$ & $\begin{array}{l}\mathbf{F} \\
\mathbf{F} \\
\mathbf{F} \\
\mathbf{F} \\
\mathbf{F} \\
\mathbf{F} \\
\mathbf{F} \\
\mathbf{F} \\
\mathbf{F} \\
\mathbf{F} \\
\mathbf{F} \\
\mathbf{F}\end{array}$ & $\begin{array}{l}\mathbf{3} \\
\mathbf{3} \\
\mathbf{3} \\
\mathbf{3} \\
\mathbf{3} \\
\mathbf{3} \\
\mathbf{3} \\
\mathbf{3} \\
\mathbf{3} \\
\mathbf{3} \\
\mathbf{3} \\
\mathbf{3}\end{array}$ & $\begin{array}{l}\text { I } \\
\text { I } \\
\text { I } \\
\text { I } \\
\text { I } \\
\text { I } \\
\text { I } \\
\text { I } \\
\text { I } \\
\text { I } \\
\text { I } \\
\text { I }\end{array}$ & $\begin{array}{l}\mathbf{F} \\
\mathbf{F} \\
\mathbf{F} \\
\mathbf{F} \\
\mathbf{F} \\
\mathbf{F} \\
\mathbf{F} \\
\mathbf{F} \\
\mathbf{F} \\
\mathbf{F} \\
\mathbf{F} \\
\mathbf{F}\end{array}$ & $\begin{array}{l}\mathbf{A} \\
\mathbf{A} \\
\mathbf{A} \\
\mathbf{A} \\
\mathbf{A} \\
\mathbf{A} \\
\mathbf{A} \\
\mathbf{A} \\
\mathbf{A} \\
\mathbf{A} \\
\mathbf{A} \\
\mathbf{A}\end{array}$ \\
\hline $\begin{array}{r}1828 \\
632 \\
931 \\
928 \\
800 \\
630 \\
31\end{array}$ & $\begin{array}{l}\mathbf{P} \\
\mathbf{r} \\
\mathbf{P} \\
\mathbf{r} \\
\mathbf{P} \\
\mathbf{r} \\
\mathbf{r}\end{array}$ & $\begin{array}{l}1 \\
1 \\
1 \\
1 \\
1 \\
2 \\
2\end{array}$ & $\begin{array}{l}\mathbf{V} \\
\mathbf{V} \\
\mathbf{V} \\
\mathbf{V} \\
\mathbf{V} \\
\mathbf{V} \\
\mathbf{V}\end{array}$ & $\begin{array}{l}\mathbf{P} \\
\mathbf{P} \\
\mathbf{N} \\
\mathbf{N} \\
\mathbf{P} \\
\mathbf{P} \\
\mathbf{N}\end{array}$ & $\begin{array}{l}\mathbf{B} \\
\mathbf{B} \\
\mathbf{B} \\
\mathbf{B} \\
\mathbf{B} \\
\mathbf{B} \\
\mathbf{B}\end{array}$ \\
\hline $\begin{array}{r}2042 \\
1812 \\
108 \\
109 \\
487 \\
5 \\
33 \\
615 \\
411\end{array}$ & $\begin{array}{l}\mathbf{P} \\
\mathbf{P} \\
\mathbf{P} \\
\mathbf{P} \\
\mathbf{P} \\
\mathbf{P} \\
\mathbf{P} \\
\mathbf{P} \\
\mathbf{P}\end{array}$ & $\begin{array}{l}2 \\
2 \\
* \\
* \\
4 \\
4 \\
4 \\
4 \\
4\end{array}$ & $\begin{array}{l}\text { II } \\
\text { II } \\
\text { II } \\
\text { II } \\
\text { III } \\
\text { IV } \\
\text { IV } \\
\text { IV } \\
\text { IV }\end{array}$ & $\begin{array}{l}\mathbf{P} \\
\mathbf{P} \\
\mathbf{P} \\
\mathbf{P} \\
\mathbf{P} \\
\mathbf{P} \\
\mathbf{P} \\
\mathbf{P} \\
\mathbf{P}\end{array}$ & $\begin{array}{l}\mathbf{B}^{\prime} \\
\mathbf{C} \\
\mathbf{C} \\
\mathbf{C} \\
\mathbf{C} \\
\mathbf{C} \\
\mathbf{C} \\
\mathbf{C} \\
\mathbf{C}\end{array}$ \\
\hline
\end{tabular}

$\mathbf{F}=$ Fortuitum; $\mathbf{P}=$ Peregrinum; $\mathbf{r}=$ strain too rough to test; $\mathbf{N}=$ type $\mathbf{N}$ (non-specific type); ${ }^{*}=$ strain did not belong to any of the four sensitin-test types.

III in the previous study has on re-examination been shown to belong to serotype I. Seven strains did not belong to any of the previously recognised types. These strains were found to possess the three species-specific antigens common to the four described serotypes, but none of the serotype-specific antigens. Studies with the antiserum prepared against one of the anomalous strains (no. 632) showed all seven strains to be identical with one another and to possess two extra antigens shared amongst themselves alone. This new serotype has been numbered V. The interrelationships between the five sero- 
types of Myco. fortuitum are shown in the figure. The results for individual strains are shown in table III.

\section{Lipid chromatography}

Two main patterns were observed, and these correspond to the Fortuitum (F) and Peregrinum (P) patterns described by Jenkins et al. (1971). Some strains, although similar to each other, did not possess the specific lipids characteristic of the above two types and are referred to as type $\mathrm{N}$ (non-specific). Table III shows that 12 were type $F, 13$ were type $P$ and three were type $N$.

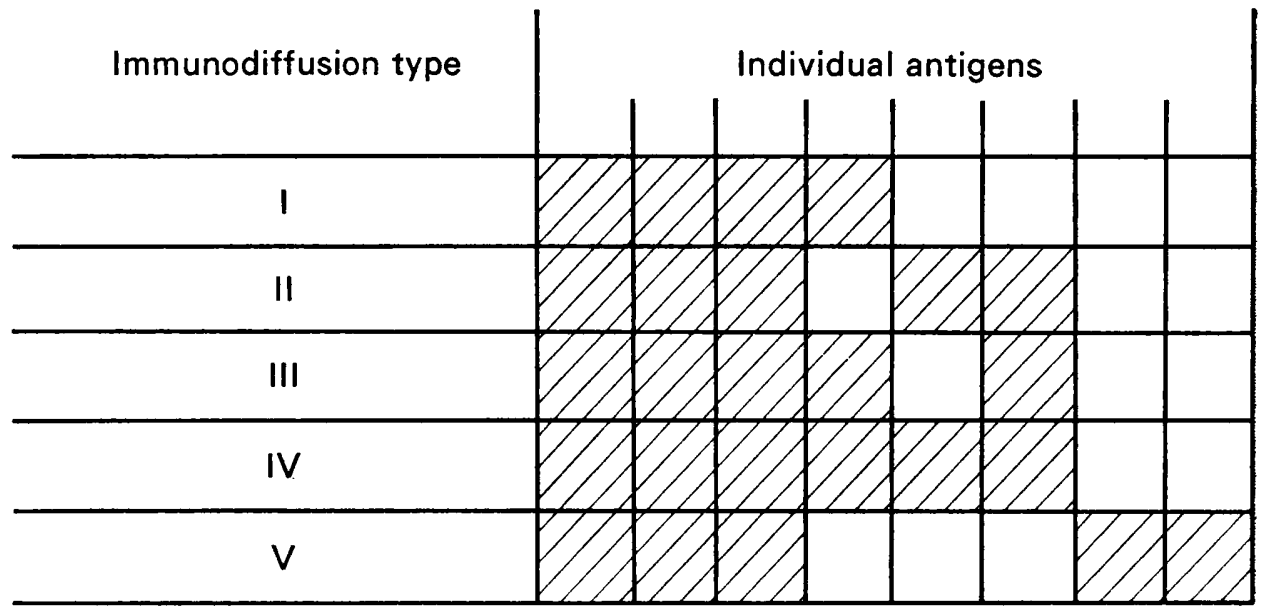

FIGURE-Diagrammatic representation of the species-specific antigens of Myco. fortuitum showing the differences between immunodiffusion serotypes. The eight or nine other demonstrable antigens that this species shares with all other species of fast-growing mycobacteria are omitted from this diagram.

\section{DisCUSSION}

The results of serotyping by three methods, biotyping and lipid typing are summarised in table III. It can be seen that there was reasonably good correlation between the different typing methods. The first group in table III was the most homogeneous, all methods of typing being in agreement. The strains of this group also had the R2 type of colonial morphology on nutrient agar and the Smf type on corn-meal agar (table I). The group included the type strains of Myco. ranae and Myco. fortuitum, and-although excluded from the present study-the type strain of Myco. minetti, ATCC no. 19542 (unpublished observations). The group also contained a strain received from Dr Bojalil as Myco. peregrinum although not the type strain.

The second group in table III, containing seven strains, was somewhat less homogeneous, although with one exception all the strains were of similar colonial appearance on nutrient agar. However, they were of more variable appearance on corn-meal agar (table I). This group contained the type strains of Myco. giae and Myco. peregrinum.

The nine strains of the third group in table III were the least homogeneous. 
The five strains of sensitin-type 4 included the strains of immunodiffusiontypes III and IV. The four strains of immunodiffusion-type II included two strains of sensitin-type 2 and the two strains that did not belong to any of the four sensitin types. All strains were of Smf appearance on corn-meal agar. Eight of the strains produced separate colonies of S, R1 and R2 type on nutrient agar and one strain (biotype $\mathrm{B}^{\prime}$ ) produced colonies of R1 and R2 alone. No type strains were included in this group.

A number of duplicate strains were unknowingly supplied by two laboratories and these provided an interesting internal control. Strains 632 and 931 were both subcultures of the type strain of Myco. peregrinum and were placed in the same sensitin and immunodiffusion types within the second group in table III. One strain was of agglutination-type $P$, and of the non-specific lipid-type $\mathbf{N}$ and the other autoagglutinated and was of lipid-type P. Strains 33 and 615 were subcultures of the same pseudolysogenic strain containing phage BK4 (Baess, 1971) and strain 411 was a culture of the same organism cured of phage. All three were almost identical, belonging to agglutinationtype $P$, sensitin-type 4 and immunodiffusion-type IV within the third group in table III. It is particularly interesting that the loss of phage made so little apparent difference to this strain.

There was a surprising degree of correlation between the three varieties of immunological tests, considering that two depend on production of humoral antibodies and one on development of cellular immunity. The three tests also depend on different types of antigen: agglutination depends on surface factors, immunodiffusion largely on cytoplasmic factors and the sensitins were prepared from culture filtrates.

The lack of complete correlation between sensitin types and immunodiffusion types in the second and third groups in table III is of interest, because it reflects internal lability especially of the third group. Further studies (Grange and Stanford, in preparation) have shown some strains of the third group to be progenitors for strains of the other two groups, and a detailed study of transitional forms is in progress.

Although this paper has concentrated on tests capable of dividing $M y c o$. fortuitum into groups, it must be realised that these groups are much more closely related to each other than they are to other fast-growing mycobacterial species. All the strains oxidised glucose, mannose and trehalose, and none oxidised arabinose, dulcitol, erythritol, galactose, rhamnose, raffinose or xylose, thus differing from Myco. smegmatis, Myco. phlei, Myco. diernhoferi and Myco. vaccae. Their ability to reduce nitrate and oxidise fructose, and their typical colonial morphology on corn-meal agar distinguished them from Myco. chelonei. All three immunological methods separated them from all other mycobacterial species, and the sharing of three species-specific antigens amongst themselves alone, shown in the immunodiffusion studies, indicated their close relationship with each other. Although sensitin-test types 1 and 3 were less closely related to each other than strains of Myco. gastri are related to Myco. kansasii (Magnusson, 1971), we do not consider that they merit separate specific status. Because strains of the first and second groups in table III have 
been separately identified in the past, it may be expedient to recommend the recognition of two subspecies. The first group would be the type subspecies Myco. fortuitum fortuitum and the second group a further subspecies Myco. fortuitum giae (peregrinum).

\section{SUMMARY}

A co-operative study of 28 cultures of Mycobacterium fortuitum by three laboratories, each using different methods, is described. Two agglutination types, four sensitin types, five immunodiffusion types, three lipids types and three biotypes were recognised amongst the strains. In most cases there was good agreement between different means of typing, and the strains could be divided into three groups. Twelve strains, including the type strains of Myco. ranae and $M y c o$. fortuitum, formed a completely homogeneous group as judged by all methods used. A second and slightly less homogeneous group of seven strains included the type cultures of Myco. giae and Myco. peregrinum, and a third group, the least homogeneous, contained nine strains of unnamed organisms. It is suggested that the first two groups might be considered subspecies, Myco. fortuitum fortuitum and Myco. fortuitum giae (peregrinum) respectively.

\section{REFERENCES}

ARonson, J. D. 1929. Spontaneous tuberculosis in snakes. J. infect. Dis., 44, 215.

BAESS, I. 1971. Report on a pseudolysogenic mycobacterium and a review of the literature concerning pseudolysogeny. Acta. path. microbiol. scand. B, 79, 428.

Bergey, D. H., Harrison, F. C., Breed, R. S., Hammer, B. W. and Huntoon, F. M. 1923. Manual of determinative bacteriology, 1st ed., Baltimore, p. 372.

Bojalil, L. F., Cerbon, J. and Trujlllo, A. 1962. Adansonian classification of Mycobacteria. J. gen. Microbiol., 28, 333.

BöNICKE, R. 1962. Identification of mycobacteria by biochemical methods. Bull. Un. int. Tuberc., 32, 13.

BöNICKE, R. 1966. The occurrence of atypical Mycobacteria in the environment of man and animal. Bull. Un. int. Tuberc., 37, 361.

DA Costa CRUz, J. 1938. Mycobacterium fortuitum, un novo bacilo acidoresistente patogenico para o homen. Acta med., Rio de J., 1, 297.

Darzins, E. 1950. Tuberculose das gias (Leptodactylus pentadactylus). Archos Inst. bras. Invest. Tuberc., 9, 29.

FURTH, J. 1926. On the serological relationship of acid-fast bacteria. J. Immun., 12, 273.

FurTh, J. AND ARONSON, J. D. 1927. On the specificity of the alcohol soluble substances of acid-fast bacteria. J. Immun., 13, 265.

GoRDON, R. E. 1937. The classification of acid-fast bacteria. J. Bact., 34, 617.

Gordon, R. E. AND SMrTh, M. M. 1953. Rapidly growing, acid-fast bacteria. 1. Species descriptions of $M$. phlei Lehmann and Neumann and $M$. smegmatis (Trevisan) Lehmann and Neumann. J. Bact., 66, 41.

Gordon, R. E. AND Minm, J. M. 1959. A comparison of four species of mycobacteria. $J$. gen. Microbiol., 21, 736.

GRIFFITH, A. S. 1930 . In A system of bacteriology, London, vol. 5, p. 326.

Jenkins, P. A., Marks, J. AND Schaefer, W. B. 1971. Lipid chromatography and seroagglutination in the classification of rapidly growing mycobacteria. Am. Rev. resp. Dis., $103,179$.

KUBICA, G. P. et al. 1972. A co-operative numerical analysis of rapidly growing mycobacteria. J. gen. Microbiol., 73, 55. 
KÜSTER, E. 1905. Über Kaltblutertuberkulose. Münch. med. Wschr., 52, 57.

MAGNUSson, M. 1971. A comparative study of Mycobacterium gastri and Mycobacterium kansasii by delayed type skin reactions in guinea pigs. Am. Rev. resp. Dis., 104, 377.

Magnusson, M. and Mariat, F. 1968. Delineation of Nocardia farcinica by delayed type skin reactions on guinea pigs. J. gen. Microbiol., 51, 151.

MARKs, J. AND SzULGA, T. 1965. Thin-layer chromatography of mycobacterial lipids as an aid to classification; technical procedures; Mycobacterium fortuitum. Tubercle, Lond., 46, 400.

MudD, S. 1925. A study by new methods of the surfaces of normal and sensitised acid-fast bacteria. Proc. Soc. exp. Biol. Med., 23, 569.

Pattyn, S. R. 1968. Serogrouping of Mycobacterium avium and "Battey " mycobacterium. Zentbl. Bakt. ParasitKde, I, Abt. Orig., 208, 449.

PatTYN, S. R. 1970. Agglutination with rapidly growing (Runyon's group IV) mycobacteria. Zentbl. Bakt. ParasitKde, I Abt. Orig., 215, 99.

Pattyn, S. R. AND Portaels, F. 1972. Identification and clinical significance of mycobacteria. Zentbl. Bakt. ParasitKde, I Abt. Orig., 219, 114.

Penso, G., Castelnuovo, G., Gaudiano, A., Princivalle, M., Vella, L. and Zampieri, A. 1952. Studi e ricerche sui micobatteri. VIII. Un nuovo bacillo tuberculare; il Mycobacterium minetti $\mathrm{n}$. sp.--studio microbiologico e patogenetico. Rc. Ist. sup. Sanità, 15, 491.

RUNYON, E. H. 1972. Conservation of the specific epithet fortuitum in the name of the organism known as Mycobacterium fortuitum da Costa Cruz. Int. J. syst. Bact., 22, 50.

Stanford, J. L. AND BeCK, A. 1968. An antigenic analysis of the mycobacteria: Mycobacterium fortuitum, Myco. kansasii, Myco. phlei, Myco. smegmatis and Myco. tuberculosis. J. Path. Bact., 95, 131.

StANFORD, J. L. AND GUNTHORPE, W. J. 1969. Serological and bacteriological investigation of Mycobacterium ranae (fortuitum) . J. Bact., 98, 375.

STANFORD, J. L. AND GUNTHORPE, W. J. 1971. A study of some fast-growing scotochromogenic mycobacteria including species descriptions of Mycobacterium gilvum (new species) and Mycobacterium duvalii (new species). Br. J. exp. Path., 52, 627.

VIRTANen, S. 1960. A study of nitrate reduction by Mycobacteria. The use of the nitratereduction test in the identification of Mycobacteria. Acta. tuberc. scand., Suppl., 48.

Wayne, L. G., Doubek, J. R. AND Russel, L. 1964. Classification and identification of mycobacteria. 1. Tests employing Tween 80 as substrate. Am. Rev. resp. Dis., 90, 588.

Whrtehead, J. E. M., Wildy, P. AND Engbaek, H. C. 1953. Arylsulphatase activity of mycobacteria. J. Path. Bact., 65, 451.

Wirson, G. S. 1925. The serological classification of the tubercle bacilli by agglutination and absorption of agglutinins. J. Path. Bact., 28, 69. 